\title{
Ensino médio: uma escola de qualidade para todos e para cada um?
}

Ruy Mello Neto* Hugo Augusto Medeiros** Maria Helena Lira***

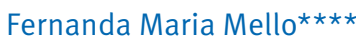
Fábio Paiva ${ }^{\star \star \star * \star}$

*(Pesquisador em Educação, Recife, CE)

**(Universidade Federal de Pernambuco, e Secretaria de Planejamento e Gestão do governo do estado de Pernambuco, Recife, PE)

$\star \star \star$ (ProfessorAdjunto - Universidade Federal Rural de Pernambuco, Recife, $\mathrm{PE})$

$\star \star \star \star$ (Pesquisadora em Educação, Recife, CE)

$\star \star \star \star \star$ (Universidade Federal de Pernambuco, Recife, PE)

$\star \star \star \star \star \star$ (Instituto de Psicologia da Universidade de São Paulo, São Paulo, SP)
Resumo: 0 objetivo deste artigo é discutir a tipologia escolar e a diversidade de oferta do ensino médio, tendo em vista a relação entre a política pública de oferta escolar e as inequidades educacionais, a partir da análise comparada entre as políticas públicas federais e estaduais dos estados do Ceará, Goiás, Pernambuco e São Paulo. Para tanto, realizamos uma análise quantitativa e qualitativa, com base nas normas das políticas públicas para o ensino médio, dos indicadores educacionais do Instituto Nacional de Estudos e Pesquisas Educacionais Anísio Teixeira (Inep), e entrevistas realizadas com educadores dos estados citados. Conclui-se que, de maneira geral, existe forte correlação entre a oferta escolar, a situação de vulnerabilidade social e as escolhas dos jovens, de acordo com o tipo de ensino médio oferecido (propedêutico e profissional), a tipologia escolar (diferentes jornadas escolares) e as distinções entre os turnos diurno e noturno.

Palavras-chave: Ensino médio. Tipologia escolar. Inequidades educacionais. Diversidade de oferta. 


\section{INTRODUÇÃO}

Quando da sua promulgação, em 2014, o Plano Nacional de Educação (PNE) estabeleceu diversas metas para a educação básica, cujos focos podem ser resumidos à garantia de acesso, ao fluxo na idade certa e à extensão do tempo pedagógico disponível aos alunos e professores (BRASIL, 2014). Uma vez que pretendemos discutir aqui a tipologia escolar e a diversidade da oferta no ensino médio, com o devido destaque às políticas de universalização do acesso, destacam-se, para o escopo deste artigo, a meta 3, sobre o ensino médio, que pretende "universalizar, até 2016, o atendimento escolar para toda a população de 15 a 17 anos e elevar, até o final do período de vigência deste PNE, a taxa líquida de matrículas no ensino médio para 85\%”, e a meta 6, sobre a educação integral, que prevê "oferecer educação em tempo integral em, no mínimo, 50\% (cinquenta por cento) das escolas públicas, de forma a atender, pelo menos, $25 \%$ (vinte e cinco por cento) dos(as) alunos(as) da educação básica”.

De acordo com Vieira (2007), a ideia de educação básica, que congrega os ensinos infantil, fundamental e médio (BRASIL, 1996), só assumiu o contorno que possui hoje no final dos anos 1980 e início dos anos 1990, tendo por mote a oferta compulsória da educação necessária ao trabalho, à cidadania e aos estudos posteriores, com base na aprendizagem de competências e habilidades (COSTA, 2011). Deve-se lembrar que, inicialmente, somente o ensino fundamental era compulsório e devia ser universalizado. Foi somente com a Emenda Constitucional n 5, de 11 de novembro de 2009 e a Lei no 12.061 , de 27 de outubro de 2009, que a situação se modificou (MELO; DUARTE, 2011; SIMÕES, 2011).

Além disso, a partir do Decreto nํㅜ 2.208/97, houve a separação entre o ensino médio propedêutico e o ensino médio profissionalizante, tendo em vista garantir uma formação profissional mais célere (BRANDÃO, 2011), em paralelo a uma formação mais generalista e humanística. $E$, apesar de o Decreto $\mathrm{n}$ 은 5.154/04 ter readmitido a relação entre ensino médio e profissionalização, esta passou a ficar a cargo dos sistemas, redes e escolas (MELO; DUARTE, 2011).

Nesta relação, o ensino médio ocupa um lugar de dificuldades persistentes no campo educacional (MELO; DUARTE, 2011), pois, mesmo com o aumento contínuo do número de concluintes do ensino fundamental (BRANDÃO, 2011), há regressão de diversos indicadores quando da transição de um nível para 
o outro: queda na taxa bruta de matrícula, aumento da distorção idade-série, redução nas taxas de matrícula líquida (estudantes matriculados na idade certa); e, considerando a exigência crescente de capacitação profissional para ingressar no mercado de trabalho (BRANDÃO, 2011), tanto a separação entre profissional e propedêutico quanto as dificuldades de acesso e permanência geram uma situação de inequidade social em que os jovens não têm acesso à educação necessária nem para o trabalho, nem para os estudos posteriores, tampouco para a cidadania. Ainda em relação ao último ponto, cumpre considerar, como faz Kuenzer (2010), que a diminuição das matrículas regulares ao longo das últimas décadas, mais o elevado número de matrículas no turno noturno e na Educação de Jovens e Adultos (EJA) têm jogado contra os objetivos de oferta de uma educação básica de qualidade.

$\mathrm{Na}$ perspectiva do governo federal, podemos citar as seguintes políticas públicas focalizadas no ensino médio, cujo ponto comum é a atuação em parceria com as secretarias estaduais:

- Programa de Melhoria e Expansão do Ensino Médio - Projeto Escola Jovem (Promed) (BRASIL, 2000): financiado pelo Banco Interamericano de Desenvolvimento, cujo foco era ampliar a cobertura, reduzir reprovação e abandono, e garantir aquisição de competências e habilidades para cidadania e trabalho. Para tanto, destinava recursos à construção e ampliação de escolas, capacitação de gestores e docentes, além de investimentos na estrutura física das escolas (bibliotecas, laboratórios, etc.).

- Programa Brasil Profissionalizado (PBP) (BRASIL, 2007): financiado pelo Fundo Nacional de Desenvolvimento da Educação, cujo foco pode ser resumido na expansão da oferta de matrículas de ensino médio integrado à educação profissional.

- Programa Ensino Médio Inovador (Proemi) (BRASIL, 2009): conectado ao Todos pela Educação ${ }^{1}$, tem foco em “apoiar e fortalecer 0 desenvolvimento de propostas curriculares inovadoras nas escolas do ensino médio não profissional" (propedêutico).

- Pacto pelo Fortalecimento pelo Ensino Médio (PFEM) (BRASIL, 2013): focado na formação dos profissionais de educação do ensino médio, com base em ações de extensão das Instituições de Ensino Superior (IES) locais.

Segundo o Art. 4ำ do Documento Orientador do PROEMI (BRASIL, 2009), poderão apresentar propostas os Estados que tenham aderido formalmente ao Plano de Metas Compromisso Todos pela Educação, de que trata o Decreto № 6.094, de 24 de abril de 2007. 
Percebe-se, então, a presença de um programa mais geral, ainda no governo Fernando Henrique (1995-2002), contraposto a programas mais focalizados, ao longo dois governos Lula (2003-2010) e Dilma (2011-) - começando pela ação para ensino médio profissional integrado, em seguida o ensino médio propedêutico, e concluindo com os profissionais de ensino. Em adição, apesar do Decreto no 5.154/04, que possibilitava a reaproximação entre propedêutico e profissional, as políticas públicas posteriores apontaram para o alargamento não só dessa divisão - com programas diferentes -, mas para orientações bastante distintas, pois, em que pese a presença, no PBP, de trecho sobre a combinação entre "formação geral, científica e cultural”, o foco do programa está na profissionalização e na articulação entre escola e arranjos produtivos locais, enquanto o Proemi tem por foco a inovação, a mudança curricular, o protagonismo juvenil e a troca de boas práticas entre escolas, inclusive com as federais.

De maneira paralela ou complementar a essas políticas, diversos estados desenvolveram, ao longo dessas duas décadas, políticas próprias para o ensino médio, com focos e perspectivas as mais diversas, mas "igualadas" pela preocupação com os resultados do Sistema de Avaliação da Educação Básica (Saeb) e das avaliações próprias (SOUSA; OLIVEIRA, 2007; BROOKE; CUNHA, 2011). Nesse sentido, destacamos os estados do Ceará, Goiás, Pernambuco e São Paulo, analisados na pesquisa "Políticas para o ensino médio: o caso de quatro estados".

De acordo com os dados do último Saeb, podemos ver que os quatro estados possuem bons resultados em relação à aprovação e à proficiência.

Tabela 1 - Indicadores de resultados

\begin{tabular}{|c|c|c|c|c|}
\hline & Ceará & Goiás & Pernambuco & São Paulo \\
\hline Saeb & 3,96 & 4,33 & 4,16 & 4,51 \\
\hline Aprovação & 83,2 & 83,8 & 84,0 & 81,5 \\
\hline Ideb & 3,6 & 3,8 & 3,6 & 3,7 \\
\hline
\end{tabular}

Fonte: MEC/Inep (2013).

Portanto, neste artigo, analisamos a tipologia educacional desses estados, com foco nos binômios médio propedêutico $x$ médio profissional, jornada ampliada $x$ jornada reduzida, turno diurno $x$ turno noturno, em busca de melhor compreender a relação entre vulnerabilidade social e oferta escolar, e entre oferta e resultados. Como base para análise, utilizamos as normas das 
políticas públicas federais e dos quatro estados, entrevistas com educadores dos quatro estados e dados quantitativos da base MEC/Inep. Ao longo do texto, pretende-se trazer atenção para a forte relação entre o tipo de ensino médio, o tipo de escola, o tipo de turno e a continuidade de inequidades sociais, a partir do caso do específico do ensino médio propedêutico integral no estado de Pernambuco.

SITUANDO A QUESTÃO: ENSINO MÉDIO, EDUCAÇÃO INTEGRAL, INEQUIDADES E VULNERABILIDADE SOCIAL

Segundo Santos (2005), território é o espaço apropriado e transformado pela ação humana, ou seja, não obstante a dimensão físico-espacial, um território abrangerá o conjunto das relações sociais que o permeiam, isso é, relações socioeconômicas, políticas e até mesmo as representações sociais que agentes (internos ou não ao território) possuem sobre ele. Em outras palavras, o que define um território e seus limites é justamente o escopo das pessoas, grupos e das relações que o compõem.

Nessa perspectiva, a situação em que sujeitos pertencentes a um determinado território não dominam um conjunto amplo de recursos socialmente produzidos, os quais lhes permitiriam atuar diante de forças e circunstâncias (externas ou internas) que proporcionam, por exemplo, o aproveitamento de oportunidades criadas no mercado, de tomada de decisões voluntárias para satisfazer suas necessidades, potencialidades e projetos, são chamados de sujeitos em situação de vulnerabilidade social (ou pertencentes a territórios vulneráveis) (KAZTMAN, 2000). Em outras palavras, um sujeito ou território vulnerável é aquele cuja pessoa ou família apresenta-se incapaz de operacionalizar oportunidades disponíveis em diferentes setores que thes permitam melhorar seu bem-estar ou evitar sua deterioração.

É impossível não relacionar a questão territorial às oportunidades e possibilidades educacionais das populações em espaços vulneráveis, de tal maneira que a constituição de hierarquias socioespaciais tende a influenciar o maior ou menor grau de vulnerabilidade. Assim, geralmente estruturadas no binômio centro-periferia, regiões mais afastadas tendem a sentir mais o efeito da territorialidade. Além do binômio acima mencionado, as desigualdades socioespaciais pautadas no entorno das escolas (mesmo quando situadas na mesma periferia) são responsáveis por uma maior incidência de iniquidade. Dessa forma, especialmente potencializadas pela setorização das matrículas e pela seletividade docente, escolas situadas em territórios vulneráveis 
tenderiam a diminuir a chance de sucesso de jovens matriculados em relação às outras escolas da mesma rede. Muitas são as possibilidades explicativas para tal efeito, dentre elas, professores que buscam melhores condições de trabalho, violência, perfil discente, entre outras. 0 ponto central é que condições do entorno escolar podem ser fator determinante para o aumento do gap de desempenho interescolas de diferentes regiões, ou seja, propiciadoras de iniquidade educacional (ALVES et al., 2013; TORRES; GOMES, 2002; KOSLINSKI; ALVES; LANGE, 2013).

Nessa perspectiva, as ampliações de políticas específicas voltadas à diminuição da iniquidade educacional podem e devem ser projetadas às redes escolares públicas. A ampliação da carga horária emerge como tendência nacional desde o governo FHC, como dito anteriormente. Assim, entender a distribuição territorial e do público dos modelos de ampliação da carga horária integral é parte fundamental ao processo de compreensão da produção da iniquidade escolar.

\section{ESCOLA INTEGRAL: ENTRE A EQUIDADE E A INIQUIDADE}

De acordo Cavaliere (2007),

Em parte significativa da literatura especializada, o aumento do tempo de escola tem sido analisado na perspectiva do "efeito escola", ou seja, dos estudos sobre resultados de desempenho escolar que independem ou superam a variável "origem sociocultural" do alunado e cuja explicação se encontra em elementos internos à vida escolar (CAVALIERE, 2007, p. 1019).

Nesse sentido, Gadotti (2010) afirma que a associação entre educação integral e qualidade da educação foi referendada em diversos momentos nas últimas décadas, com diversos estados (CAVALIERE, 2007) fortalecendo suas redes integrais, apostando no impacto positivo que isso traria. Todavia, apesar de concordarem quanto à importância, cada estado brasileiro jogou suas fichas em modelos diferentes de educação integral (CAVALIERE, 2007), conforme mostra a Tabela 2, para os estados abrangidos pela pesquisa. 
Tabela 2 - Quadro resumo das matrículas

\begin{tabular}{|c|c|c|c|}
\hline & Ceará & Goiás & Pernambuco \\
\hline Matrículas EM (2014) & 340.894 & 213.928 & 332.017 \\
\hline \multicolumn{4}{|c|}{ JORNADA INTEGRAL } \\
\hline $\begin{array}{l}\text { Matrículas em Turmas Integrais } \\
\qquad(2014)\end{array}$ & $\begin{array}{l}42.235 \\
(12,4 \%)\end{array}$ & $\begin{array}{l}4.663 \\
(2 \%) \\
\end{array}$ & $\begin{array}{c}116.825 \\
(35 \%)\end{array}$ \\
\hline $\begin{array}{c}\text { Matrículas em Médio Técnico } \\
\text { Integrado de Tempo Integral (2014) * }\end{array}$ & $\begin{array}{c}40.820 \\
(12 \%)\end{array}$ & $\begin{array}{c}0 \\
(0 \%)\end{array}$ & $\begin{array}{l}7.814 \\
(2,4 \%)\end{array}$ \\
\hline \multicolumn{4}{|c|}{ TURNO NOTURNO } \\
\hline Matrículas no Turno Noturno (2014) & $\begin{array}{l}69.847 \\
(21 \%)\end{array}$ & $69.918(33 \%)$ & $\begin{array}{l}90.659 \\
(27 \%) \\
\end{array}$ \\
\hline $\begin{array}{l}\text { Diferença entre Saeb de turmas } \\
\text { diurnas e noturnas (2013) ** }\end{array}$ & $\begin{array}{l}1,55 \\
\text { SIG. } 0,000 \\
\text { ETA } 38 \%\end{array}$ & $\begin{array}{c}0,83 \\
\text { SIG 0,000 } \\
\text { ETA 31\% }\end{array}$ & $\begin{array}{c}1,65 \\
\text { SIG 0,000 } \\
\text { ETA 45\% }\end{array}$ \\
\hline \multicolumn{4}{|c|}{ ESCOLAS RURAIS } \\
\hline Matrículas em Escolas Rurais (2014) & $\begin{array}{l}11.372 \\
(3,3 \%)\end{array}$ & $3.198(1,5 \%)$ & $\begin{array}{l}17.582 \\
(5,3 \%) \\
\end{array}$ \\
\hline $\begin{array}{c}\text { Matrículas em Turmas Integrais de } \\
\text { Escolas Rurais (2014) }\end{array}$ & 2.004 & - & 2.959 \\
\hline $\begin{array}{l}\text { Diferença entre Saeb de turmas de } \\
\text { escolas urbanas e rurais (2013) ** }\end{array}$ & $\begin{array}{c}0,78 \\
\text { SIG. } 0,000 \\
\text { ETA } 11 \%\end{array}$ & $\begin{array}{c}0,21 \\
\text { SIG. 0,136 } \\
\text { ETA 4\% }\end{array}$ & $\begin{array}{c}0,77 \\
\text { SIG. } 0,000 \\
\text { ETA } 9 \%\end{array}$ \\
\hline \multicolumn{4}{|c|}{ EDUCAÇÃO DE JOVENS E ADULTOS } \\
\hline Matrículas EJA (Presencial) & 15.411 & 22.010 & 51.445 \\
\hline Matrículas EJA (Semipresencial) & 30.660 & 0 & 101 \\
\hline
\end{tabular}

Fonte: Ministério da Educação (MEC, 2013, 2014²). *As matrículas de técnico integrado representam a fatia de matrículas integrais que vêm do ensino técnico. **Foram usadas as médias das notas padronizadas.

2 Foram consideradas integrais as turmas com 420 minutos (7 horas) ou mais de jornada. 
Como percebemos pela Tabela 2, os estados possuem perfis diferentes de matrículas e apostam em modelos diferentes de educação integral, os quais se relacionam com: 1. o tipo de integralidade (mesma instituição ou instituições distintas); 2. o tipo de ensino (propedêutico ou técnico); 3. o tipo de currículo (aumento de carga horária em disciplinas escolares ou atividades extraescolares); 4. relação com a matrícula em turno noturno (que se coloca, frequentemente, como a antípoda do ensino integral).

Ainda assim, na perspectiva dos impactos da ampliação da carga horária escolar, a Tabela 3 aponta para um padrão comum às escolas integrais, ou seja, percebemos que, sobretudo para o Ceará, a média de horas-aula e o Indicador de Nível Socioeconômico das Escolas de Educação Básica (Inse) caminham no mesmo sentido.

Tabela 3 - Correlação entre média de horas-aula e aprovação, distorção idade-série e nível socioeconômico

\begin{tabular}{|c|c|c|c|c|}
\hline & \multicolumn{4}{|c|}{ Média de horas-aula } \\
\cline { 2 - 5 } & Ceará & Goiás & Pernambuco & São Paulo \\
\hline $\begin{array}{c}\text { Distorção } \\
\text { idade-série }\end{array}$ & $-0,68$ & $-0,47$ & $-0,77$ & $-0,26$ \\
\hline Aprovação & $+0,59$ & $+0,12$ & $+0,39$ & $+0,22$ \\
\hline Inse & $+0,32$ & $+0,16$ & $-0,02$ & $+0,16$ \\
\hline
\end{tabular}

Fonte: Elaborada pelos autores, com base em MEC/Inep (2013, 2014).

Além disso, de maneira geral, excetuando São Paulo, as escolas integrais apresentam menor distorção idade-série, bem como o aumento da carga horária caminha junto ao crescimento das taxas de aprovação em todos os estados.

De forma complementar, há, segundo Sousa e Oliveira (2008), o indicativo de que alunos das escolas integrais tendem a ter um perfil homogêneo em relação ao tipo de juventude, qual seja, de predominância não economicamente ativa - diferente, por exemplo, do ensino noturno, que tem um perfil com maior presença de alunos economicamente ativos - "trabalhador-estudante"3. Assim, acreditamos ser possível inferir que, embora as escolas integrais colaborem para melhores resultados, têm atraído um perfil específico de jovem e contribuído pouco para reduzir inequidades relativas ao acesso escolar e ao turno de estudo.

3 Além da maior presença de estudantes que retornam à escola depois de interrupções nos estudos, de estudantes que ainda são jovens e que ainda possuem a escola como principal lugar de socialização. 
Em outras palavras, uma maior quantidade de escolas integrais implica maior participação de um público "selecionado" na rede estadual, o que, por um lado, potencializa as oportunidades de acesso, mas, por outro, a depender do percentual de estudantes matriculados em escolas integrais na rede, pode criar uma espécie de hierarquização interna à rede, dividindo a rede entre: (a) escolas com alunos cujo perfil permite estudar em escolas integrais e (b) escolas com os demais estudantes.

Apontamos isso, pois, a título de ilustração, quando consideramos o alunado noturno, percebemos que as notas padronizadas no Saeb (MEC/INEP, 2013) são em média 0.99 ponto mais baixos que os das turmas diurnas em São Paulo, 1.65 em Pernambuco, 1.55 pontos no Ceará e 0.83 pontos em Goiás (ver Tabela 2) ${ }^{4}$. Ou seja, inferimos aqui que um maior percentual de alunos em escolas integrais significa um aumento de desempenho médio da escola e que, de acordo com o modelo de expansão das matrículas integrais, é possível dizer se esse aumento possibilita uma diminuição da iniquidade escolar ou se apresenta a criação de uma elite interna à rede que potencializa essa iniquidade.

TIPOLOGIAS, TERRITÓRIO E INEQUIDADE: SITUANDO OS QUATRO ESTADOS ANALISADOS

Pelo quadro apresentado no início deste artigo, percebemos que a rede estadual de Pernambuco possui o maior número de matrículas em tempo integral, as quais estão concentradas no ensino médio propedêutico - o qual, como veremos mais adiante, é realizado com base em modelo e recursos próprios e não do Proemi. Além disso, percebe-se que os estados com menos matrículas integrais também são os que possuem maior número de alunos no turno noturno - mesmo porque, em geral, as turmas integrais são diurnas e vespertinas.

Chama a atenção também o estado do Ceará, que possui suas matrículas integrais concentradas em escolas técnicas. Nesse sentido, apoiado no Programa Brasil Profissionalizado, o governo do Estado do Ceará, a partir

\footnotetext{
Nesse ponto, destaca-se que o modelo de tipologia bastante diversa de Goiás, com predominância de escolas regulares de três turnos, termina por lidar melhor com a inequidade entre os turnos diurno e noturno. Em contraponto, São Paulo apresenta a maior inequidade neste caso, não obstante seu elevado número de matrículas no turno noturno. Mas, em todos os casos, a proficiência dos alunos é menor no turno noturno, que sofre com questões como carga horária reduzida e falta de proposta pedagógica específica (GONÇALVES; PASSOS; PASSOS, 2005).
} 
do ano de 2007, adota uma agressiva estratégia de expansão do seu ensino médio profissional, por meio da construção, reforma ou ampliação de 106 escolas técnicas em 82 municípios. Essas escolas, com funcionamento em regime integral, oferecem, ao todo, 53 cursos diferentes.

Essa agressiva estratégia amplia fortemente o número absoluto de matrículas nessa modalidade de ensino, uma vez que dados de matrícula referentes aos anos entre 2007 e 2014 mostram uma taxa de crescimento na oferta de aproximadamente $4.700 \%$. Desse modo, em 2007, ainda sem uma oferta de educação profissional integrada ao ensino médio, havia apenas 914 alunos matriculados nessa modalidade de ensino, contra os 44.707 em 2014. Além disso, antes de 2007 sequer havia alguma matrícula na referida modalidade.

Por outro lado, mesmo com o modelo de expansão adotado, a Secretaria de Educação do Estado do Ceará mantém a oferta da modalidade de ensino regular. Assim, cria-se um sistema de ensino com dupla oferta de modalidades: uma regular, que funciona com base em gestões (financeira, administrativa e pedagógica) definidas antes da ampliação da oferta; e uma rede de escolas de educação profissional, com gestões próprias e criadas a partir de então.

Apesar da expansão, as matrículas da rede estadual concentram-se em escolas regulares. Apenas cerca de $12 \%$ da oferta é feita em escolas técnicas, sendo que, dos 691 estabelecimentos de ensino, 106 são de educação profissional. Tal informação, associada ao dado de matrícula, mostra que escolas de educação profissional atendem menos alunos, uma vez que, enquanto uma escola integral atende, em média, 386 alunos por escola, uma equivalente em educação regular atende 511.

É importante destacar que o estado do Ceará conta com um modelo complementar de instituição de ensino médio. Por meio da oferta de matrículas em espaços distantes da sede da escola, são estabelecidos os centros de extensão rural ou anexos - esses quase sempre com estrutura (física e de capital humano) pior do que a sede oficial da instituição (referência). Dados da Secretaria de Educação (2015) mostram que aproximadamente 35 mil alunos estão matriculados em instituições como essas, o que se aproxima do número de estudantes matriculados em instituições técnicas. Além disso, muitas vezes, as extensões atendem o turno noturno, o qual, como já vimos, tende a conseguir resultados piores.

Nesse ponto, é importante destacar, inclusive, a formatação da matrícula nas escolas profissionais, que se dá com base no histórico escolar do aluno ao 
longo do ensino fundamental, de acordo com a divisão de vagas 80-20, para alunos de escola pública (CEARÁ, 2016). Desse modo, alunos com notas ruins em seu histórico escolar possuem menores condições de acessar a educação integral.

Assim, a existência de uma dupla (ou tripla) oferta na rede regular, com destaque para o número alto de alunos matriculados em escolas de menor prestígio, coloca a hierarquização e a busca pela redução da iniquidade em um patamar diferente. Se há uma adoção pela expansão do ensino médio integral profissional, é inegável que a massiva quantidade de matrículas é feita em instituições que não estas - e, mesmo com uma representativa quantidade de alunos, está matriculada em instituições que atendem um perfil de alunos sujeito a inequidades persistentes. Caso não haja modificação do cenário, caminha-se para a criação de uma elite educacional interna à rede, com nível superior (integral técnico), intermediário (regular com locus na sede social da instituição) e as instituições anexas representando o nível inferior.

Em outras palavras, o governo cearense ataca o problema da qualidade da oferta sem, com isso, afetar diretamente a distribuição equânime de oportunidades. Assim, ainda que pese positivamente ao modelo o fato de a distribuição de escolas profissionais levar em conta a distribuição geográfica (com oferta em regiões vulneráveis), a ausência de uma política que proporcione o acesso de uma quantidade maior de jovens às instituições de excelência, bem como a garantia da possibilidade de acesso a qualquer estudante, termina levando o governo cearense a falhar no ataque à iniquidade escolar na rede estadual.

Diferente do estado cearense, em Goiás a diversidade na tipologia de instituições é uma marca importante do modelo de gestão. Na rede estadual as escolas podem ser classificadas ${ }^{5}$ como: regulares; colégios da polícia militar; ensino médio profissional; centro de ensino em período integral e escolas conveniadas. Cada uma das modalidades conta com características específicas no que concerne desde o financiamento até o órgão responsável por sua gestão - o que é visto pela Secretaria como uma resposta às necessidades específicas de cada alunado, conforme um informante, em entrevista concedida ${ }^{6}$ em 2015 ao grupo de pesquisadores do Cenpec:

Escolas ainda podem oferecer cursos de Educação de Jovens e Adultos.

Entrevista concedida em junho de 2015. Entrevistador: Equipe Goiás. Goiânia, 2015. 1 arquivo .mp3 
Acaba que existem muitas especificidades na rede, você começa a ver. Uma escola de tempo integral tem suas especificidades, os colégios militares têm outras especificidades, a escola rural também tem uma especificidade. As próprias escolas de tempo parcial urbano têm suas especificidades, tanto em relação ao noturno e ao EJA, quanto ao contexto socioeconômico em que a escola está inserida. Enfim, existem todas essas especificidades [...] (Goiás, alto cargo da secretaria estadual de educação).

Dentre as categorizações que marcam cada uma das modalidades, destacamos que:

1) as escolas de ensino médio regular representam 627 instituições no estado, das quais aproximadamente $87 \%$ oferecem também turmas de ensino fundamental. Não há horário ampliado e todas elas contam com três turnos;

2) os colégios da polícia militar somam 25 instituições, localizadas na região metropolitana de Goiânia ou em outras cidades de grande porte. Fazem parte do programa criado oficialmente pela lei estadual no 14.050, embora já funcionem efetivamente desde o ano de 1999. Contam com processo seletivo, resguardando $50 \%$ das vagas para filhos de militares. A gestão das escolas é de responsabilidade compartilhada entre a Secretaria de Segurança Pública, a Polícia Militar de Goiás e a Diretoria de Ensino, Instrução e Pesquisa - embora prédios e professores sejam disponibilizados pela Secretaria Estadual de Educação;

3) as escolas de ensino médio profissional representam apenas oito instituições estaduais. Elas oferecem ensino profissionalizante concomitante com o ensino regular ou com o pós-médio. Sua gestão é de responsabilidade da Secretaria de Estado de Ciência, Tecnologia e Inovação;

4) os centros de ensino em período integral contam com 23 escolas, horário integral (7h30 às 17h) e currículo próprio - com atividades como: esportes, dança, artes, informática e reforço escolar. Os professores são contratados sob a exigência de serem licenciados e recebem uma gratificação por trabalharem em tempo integral. Esse tipo de instituição é integrado ao Programa Novo Futuro, do governo federal;

5) as escolas conveniadas são àquelas ligadas à rede privada de educação básica. Dessa forma, o estado oferece capital humano e a mantenedora oferece a estrutura física do local, os materiais pedagógicos e os materiais. A direção da escola cabe ao responsável privado, entretanto, a orientação pedagógica e o monitoramento dos professores são de responsabilidade da Secretaria de Educação. As instituições podem cobrar mensalidades dos 
estudantes, por isso aparecem como instituições privadas nos registros do MEC. Nesse caso, de acordo com a Secretaria, a prioridade é para áreas com altos índices de violência.

Por outro lado, como visto na descrição das diferentes tipologias, ainda é evidente a predominância do modelo de escolas regulares. Essas representam a esmagadora maioria das instituições de ensino médio público no estado. Além disso, as escolas regulares são as que apresentam piores resultados nas avaliações externas e as escolas não regulares concentram-se na grande Goiânia e em cidades maiores - o que não contribui para reduzir as inequidades de tipo urbano x rural. Desse modo, assim como no caso do estado do Ceará, apesar da expressiva diversidade, o modelo não é capaz de impactar diretamente a iniquidade da oferta.

Ademais, como em outros estados, a condição dos professores de escolas integrais é diferenciada, pois eles recebem gratificação específica ${ }^{7}$ e trabalham em regime de dedicação exclusiva, podendo focar em somente uma escola. De maneira semelhante a Pernambuco e São Paulo, a escola integral oferece não só tempo ampliado para os alunos, mas melhores condições de trabalho e valorização profissional para os professores.

No que se refere ao ensino noturno de Goiás, percebe-se uma preocupação presente, que envolve não somente ações diretamente conectadas à educação, mas a outras áreas, como no caso do aplicativo de informações sobre Goiás, que permite aos alunos saberem, por exemplo, o horário do ônibus que os leva à escola.

Finalmente, no caso das escolas rurais, nota-se a presença de atendimento difuso, que se estende para povoados vizinhos. Além disso, a caracterização do MEC, no que tange ao fato de a escola ser rural ou não, é percebida como insuficiente para lidar com o perfil dos alunos, pois há escolas urbanas cujo perfil de alunado é de moradores de área rural, como evidencia a fala de um entrevistado de Pernambuco ${ }^{8}$ :

Gratificação de Dedicação Exclusiva para os professores das escolas de referência, nos valores de $R \$ 2.032,00$ (integral/40 horas) e $R \$ 1.623,00$ (semi-integral/32 horas) (PERNAMBUCO, 2008). Para os professores de ensino médio fora das escolas de referência, o vencimento-base corresponde a $R \$ 1.438,33$ e $R \$ 1.917,78$ (valor do piso nacional), de acordo com o regime de 150 ou 200 horas . Já os professores temporários da rede regular recebem $R \$ 1.273,34$ e $R \$ 1.698,09$ (SINTEPE, 2015).

8 Entrevista concedida em junho de 2015. Entrevistadora: Fernanda Mello. Recife, 2015. 1 arquivo .mp3 
Apesar de termos o distrito, o nosso alunado vem da zona rural [...] Sendo assim, a gente trata nossa escola como de zona rural, principalmente por essa oferta para os alunos. Às vezes, alguém pode dizer: "Mas aqui é uma zona urbana". Mas nosso alunado, em sua maioria, é da zona rural [...] É um distrito de Niquelândia, logo após o rio, na divisa com o município. Lá não tem escola, eles iriam para dentro do município deles, que está a $30 \mathrm{~km}$, onde se faz tudo. Mas quanto à demanda dos pais, eles não quiseram de forma alguma, questionaram e correram atrás para trazerem os filhos para cá, até mesmo pela organização da escola. Se existem pais que valorizam a escola são eles, porque eles sentiram a necessidade de trazer os filhos para cá [...]

(Pernambuco, alto cargo de órgão regional).

Além disso, apesar de uma política pública orientar-se para a construção de determinado sentido, sua tradução e apropriação em práticas seguem trajetórias complexas e diversas (MAINARDES; MARCONDES, 2009), que variam de acordo com o conjunto de capitais e habitus envolvidos. Assim, conforme afirmam Costa e Koslinski (2012), no caso da decisão sobre as escolas na qual matricularão seus filhos, os familiares, frequentemente, resistem às tendências naturais de oferta (como matrícula em escola próxima à residência), tendo em vista matricularem seus filhos em escolas nas quais confiam, e, notadamente, em escolas que acreditam poderão ajudar seus filhos a obter bons prêmios educacionais (RESENDE; NOGUEIRA; NOGUEIRA, 2011).

No caso paulista, o governo do estado adota três tipologias de ensino médio, com destaque para a quantidade de matrículas em uma delas: o ensino médio regular, com a esmagadora maioria das matrículas e que oferece aulas em um único turno; o Programa de Ensino Integral (PEI), com uma pequena quantidade de matriculados, e que conta com horário integral e disciplinas não profissionalizantes no contraturno; e, concomitantemente, a oferta de turmas de Educação de Jovens e Adultos - Ensino Médio (EJA-EM).

Além disso, há estudantes remanescentes de outra modalidade, que, apesar de oficialmente desativada, conta com alunos em fase de conclusão: as Escolas de Tempo Integral (ETIs), que oferecem ensino médio regular em um turno e oficinas no contraturno. Nesse sentido, destaca-se a mudança na concepção do estado acerca da educação integral, que passou de um alinhamento com a ideia de atividades extracurriculares no contraturno (modelo ETI) para um modelo de fortalecimento de carga horária disciplinar no contraturno (modelo PEI). De forma complementar, sem vínculo com a Secretaria de Educação, o governo do estado mantém ainda algumas escolas de ensino profissionalizante, ofertado por instituições parceiras do governo.

Em resumo, o governo de São Paulo mantém uma rede de ensino médio regular 
com 3.806 escolas (ou aproximadamente $86 \%$ das instituições) e conta ainda com 267 escolas de tempo integral. Dentre essas escolas, 1.600 também oferecem turmas de EJA-EM. Ou seja, exatamente como ocorre nos demais estados, no que se refere à questão da iniquidade, trata-se de um modelo que elege uma pequena elite de privilegiados ao acesso do ensino integral, não apresentando, portanto, grande transformação ou grande poder de inclusão/ redução de iniquidade.

Retomando o caso de Pernambuco, com evidente destaque no que se refere à implantação de um modelo de educação integral, o estado apresenta um modelo que difere dos demais analisados, cujas redes integrais representam uma pequena parte da oferta. Com matrículas concentradas em cidades maiores, a rede integral pernambucana conta com maior capilarização e alcance da oferta integral. Nesse sentido, podemos destacar o fato de todos os municípios do estado possuírem escolas integrais, enquanto no Ceará este número é de 45\%, em São Paulo 23,6\%, e em Goiás 5,7\%.

Desde 2007, a rede estadual tem direcionado suas políticas de ensino médio para a integralização da carga horária escolar por meio das "escolas de referência”. Após o processo inicial de ampliação, o estado atingiu um percentual de $37 \%$ de suas escolas com funcionamento integral - o que representa o maior percentual do país entre as unidades da federação. Essas escolas se dividem entre escolas integrais e semi-integrais, nas quais os alunos recebem aulas em uma perspectiva da educação interdimensional, com currículos que contemplam não só as disciplinas comuns, mas inclusive disciplinas diversificadas.

Some-se a isso o fato de que o modelo de expansão adotado pelo governo pernambucano levou em consideração, dentre outros, a distribuição espacial equitativa, de forma a garantir uma escola integral ou semi-integral em todos os municípios do estado. Assim, as escolas de referência, que se apresentam entre as com melhores resultados da rede, estão presentes em todos os municípios do estado, o que, naturalmente, modifica a relação entre escolas de bom desempenho e territorialidade, já que a educação integral é, com isso, garantida aos municípios de estratos mais vulneráveis.

Além disso, com o modelo de expansão, o governo do estado terminou por criar uma nova tipologia de escolas, dividindo a educação integral entre escolas de referência (com ensino não técnico no contraturno e sem seleção de alunos) e técnicas (com ensino profissional técnico integrado e seleção de alunos). Entre outras vantagens, a rede integral (técnica ou de referência) 
conta com número maior de professores efetivos e uma bonificação salarial aos funcionários pela carga horária ampliada. Assim, ao menos no que se refere à diminuição da iniquidade via acesso à educação integral, a rede estadual pernambucana foi aquela que apresentou um modelo com maior alcance e diversidade de público-alvo.

\section{CONCLUSÕES}

Se considerarmos especificamente as escolas integrais, vemos que essas possuem melhores resultados de aprovação, além de terem menor distorção idade-série. Contudo, a análise comparada entre o nível socioeconômico das escolas e a quantidade de horas-aula mostra que, com exceção de Pernambuco, os estados tendem a ter seus alunos de estratos socioeconômicos mais altos matriculados nas escolas com maior carga horária de aula.

Assim, de modo geral, percebe-se que os diferentes modelos de oferta escolar não são particularmente determinantes nem para a redução geral das inequidades escolares nem para o desempenho da rede, pois enquanto o Ceará aposta em escolas profissionalizantes, Pernambuco em escolas propedêuticas, Goiás em tipologias específicas para casos específicos e São Paulo em escolas regulares e de EJA, todos os estados possuem resultados expressivos.

No tocante às inequidades, o modelo capilarizado de escolas integrais de Pernambuco, com ensino propedêutico em escolas sem seleção para entrada (apesar de um perfil homogêneo de jovens sem distorção idade-série) tem-se mostrado o mais adequado para lidar com as inequidades de localidade (do tipo urbano $x$ rural) e de fundo socioeconômico, enquanto o modelo de tipo específico de Goiás, aliado ao ensino regular de três turnos, tem-se mostrado adequado para reduzir inequidades de turno (tipo diurno $\mathrm{x}$ noturno). Por outro lado, o modelo cearense, com ensino técnico por meio de seleção para ingresso, revela-se o que menos contribui para reduzir inequidades de localidade, socioeconômica e entre os turnos de ensino. 


\section{Secondary education: a quality education for each and every student?}

Abstract: The goal of this article is to discuss the school typology and the diversity of education offer in secondary education, considering the relationship between public policies for education offer and educational inequalities, based on a comparative analysis between federal and state policies in the states of Ceará, Goiás, Pernambuco and São Paulo. To that end, we conducted a quantitative and qualitative analysis of the norms of public policies on secondary education, educational indicators collected from the Instituto Nacional de Estudos e Pesquisas Educacionais “Anísio Teixeira” (Inep), and interviews conducted with educators in the four states above. We found that, in general, there is a strong correlation between education offer, social vulnerability situations, and youths' choices, according with the type of secondary education offer (propaedeutic and vocational), school typology (different school hours), and the distinctions between day school and night school.

Keywords: Secondary education. School typology. Educational inequalities. Diversity of education offer. 


\section{Enseñanza media: ¿una escuela de calidad para todos y para cada uno?}

Resumen: El propósito de este artículo es discutir la tipología escolar y la diversidad de oferta de la enseñanza media, teniendo en cuenta la relación entre la política pública de oferta escolar y las inequidades educacionales, a partir del análisis comparado entre las políticas públicas federales y estatales (provinciales) de los estados de Ceará, Goiás, Pernambuco y São Paulo. Para ello, realizamos un análisis cuantitativo y cualitativo, con base en las normas de las políticas públicas de enseñanza media, en los indicadores educacionales del Instituto Nacional de Estudios e Investigaciones “Anísio Teixeira” (Inep), y en entrevistas realizadas con educadores de los cuatro estados citados. Se concluye que, en general, existe una fuerte correlación entre la oferta escolar, la situación de vulnerabilidad social y las elecciones de los jóvenes, de acuerdo con el tipo de enseñanza media ofrecida (propedéutica y profesional), la tipología escolar (diferentes jornadas escolares) y las distinciones entre los turnos diurno y nocturno.

Palabras clave: Enseñanza media. Tipología escolar. Inequidades educacionales. Diversidad de oferta. 


\section{REFERÊNCIAS}

ALVES, L.; PADILHA, F.; BATISTA, A. A. G.; ÉRNICA, M.; CARVALHO-SILVA, H. H. Desigualdades socioespaciais e concorrência entre professores por escolas. Goiânia: Anped, set./out. 2013.

BRANDÃO, C. O ensino médio no contexto do plano nacional de educação: 0 que ainda precisa ser feito. Cadernos Cedes, Campinas, v. 31, n. 84, p. 195208, maio-ago. 2011.

BRASIL. Lei de Diretrizes e Bases da Educação Nacional.Brasília, 1996. Disponível em: 〈http://www.planalto.gov.br/ccivil_03/leis/L9394.htm〉. Acesso em: maio 2016.

. Ministério da Educação. Programa de Melhoria e Expansão do Ensino Médio - Projeto Escola Jovem. Brasília, 2000. Disponível em: 〈http://portal. mec.gov.br/setec/arquivos/pdf/Escola\%20Jovem.pdf〉. Acesso em: maio. 2016.

- Ministério da Educação. Brasil profissionalizado. Brasília, 2007. Disponível em: 〈http://www.planalto.gov.br/ccivil_03/_Ato2007-2010/2007/ Decreto/D6302.htm>. Acesso em: maio 2016.

. Ministério da Educação. Programa Ensino Médio Inovador. Brasília, 2009. Disponível em: 〈http://portal.mec.gov.br/index.php?option=com docman\&view=download\&alias=13249-doc-orientador-proemi2013-novopdf\&category_slug=junho-2013-pdf\&Itemid=30192〉. Acesso em: maio 2016.

- Ministério da Educação. Pacto pelo Fortalecimento pelo Ensino Médio. Brasília, 2013. Disponível em: 〈http://portal.mec.gov.br/index. php?option=com_docman\&view=download \&alias=12498-portariaalfabetiza-070213-pdf\&category_slug=fevereiro-2013-pdf\&Itemid=30192〉. Acesso em: maio 2016.

. Plano Nacional de Educação 2014-2024 [recurso eletrônico]: Lei nº 13.005, de 25 de junho de 2014, que aprova o Plano Nacional de Educação (PNE) e dá outras providências. Brasília: Câmara dos Deputados, Edições Câmara, 2014. (Série legislação; n. 125, 86 p.)

BROOKE, N.; CUNHA, M. A. A. A avaliação externa como instrumento da gestão educacional nos estados. São Paulo: Fundação Victor Civita, 2011.

CAVALIERE, A. Tempo de escola e qualidade na educação pública. Educação \& 
Sociedade, Campinas, v. 28, n. 100 - Especial, p. 1015-1035, out. 2007.

CEARÁ. Edital de Admissão de Alunos. Fortaleza: Secretaria de Educação do Estado do Ceará, 2016.

COSTA, F. Escola pública e ensino médio: formação da juventude na perspectiva dos documentos oficiais nacionais na educação básica (1996-2009). 2011. 213 f. Dissertação (Mestrado em Educação)-Universidade Estadual de Campinas, Campinas, 2011.

COSTA, M.; KOSLINSKI, M. Escolha, estratégia e competição por escolas públicas. Pró-Posições, Campinas: Unicamp, v. 23, n. 2, p. 195-213, 2012.

GADOTTI, M. Qualidade na educação: uma nova abordagem. São Paulo: Instituto Paulo Freire, 2010.

GONÇALVES, L.; PASSOS, S.; PASSOS, A. Novos rumos para o ensino médio noturno - como e por que fazer? Ensaio: Avaliação e Políticas Públicas em Educação, Rio de Janeiro, v. 13, n. 48, p. 345-360, jul./set. 2005.

INEP/MEC. Instituto Nacional de Estudos e Pesquisas Educacionais Anísio Teixeira/Ministério da Educação e Cultura. Resultados do Saeb/2012: resultados estaduais. Brasília, s/d [c].

KAZTMAN, R. Notas sobre la medición de la vulnerabilidad social. México: BID-Birf-Cepal, 2000. Borrador para discusión. 5 Taller regional, la medición de la pobreza, métodos e aplicaciones. Disponível em: 〈www.eclac.cl/deype/ noicias/proyectos>. Acesso em: maio 2016.

KOSLINSKI, M.; ALVES, F.; LANGE, W. Desigualdades educacionais em contextos urbanos: um estudo da geografia de oportunidades educacionais na cidade do Rio de Janeiro. Educação \& Sociedade, Campinas, v. 34, n. 125,, p. 200-220, 2013.

KUENZER, A. O ensino médio no Plano Nacional de Educação 2011-2020: superando a década perdida? Educação \& Sociedade, Campinas, v. 31, n. 112, p. 851-873, jul./set. 2010.

MAINARDES, J.; MARCONDES, M. Entrevista com Stephen J. Ball: um diálogo sobre justiça social, pesquisa e política educacional. Educação \& Sociedade, Campinas, v. 30, n. 106, p. 303-318, jan./abr. 2009.

MARTINS, A. Análise dos impactos das condições de transporte escolar rural no 
rendimento dos alunos. 2010. 118 f. Dissertação (Mestrado em Transportes)Universidade de Brasília, Brasília, 2010.

MEC/INEP. Ministério da Educação. Instituto Nacional de Estudos e Pesquisas Educacionais “Anísio Teixeira”. Microdados do Censo Escolar da Educação Básica 2006. Brasília: MEC/Inep, 2013.

Ministério da Educação. Instituto Nacional de Estudos e Pesquisas Educacionais “Anísio Teixeira”. Microdados do Censo Escolar da Educação Básica 2006. Brasília: MEC/Inep, 2014.

MELO, S.; DUARTE, A. Políticas para o ensino médio no Brasil: perspectivas para a universalização. Cadernos Cedes, Campinas, v. 31, n. 84, p. 231-251, maio-ago. 2011.

PERNAMBUCO. Lei Complementar no 130, de 19 de setembro de 2008. Introduz alterações na Legislação indicada, e dá outras providências. Recife: Alepe, 2008.

RESEndE, T. F.; NOGUEIRA, C. M. M.; NOGUEIRA, M. A. Escolha do estabelecimento de ensino e perfis familiares: uma faceta a mais das desigualdades escolares. Educação \& Sociedade, Campinas, v. 32, n. 117, p. 953-970, out./dez. 2011.

SANTOS, M. O retorno do território. OSAL - Observatorio Social de América Latina, Buenos Aires: Clacso, año 6, n. 16, jun. 2005. Disponível em: 〈http:// bibliotecavirtual.clacso.org.ar/ar/libros/osal/osal16/D16Santos.pdf». Acesso em: maio 2016.

SIMÕES, C. Políticas públicas do ensino médio: iniciativas governamentais e o ensino médio inovador. Revista Retratos da Escola, Brasília, v. 5, n. 8, p. 111-125, jan./jun. 2011.

SINTEPE. Grade de vencimento base do grupo ocupacional magistério - cargo público de professor. Recife: Sintepe, 2015.

SOUSA, S.; OLIVEIRA, R. Sistemas de Avaliação no Brasil: características, tendências e usos dos resultados. São Paulo: Universidade de São Paulo, 2007.

Ensino médio noturno: democratização e diversidade.

Educar, Curitiba, v. 1, n. 31, p. 53-72, 2008. 
TORRES, H. G.; GOMES, S. Desigualdade educacional e segregação social. Novos Estudos, São Paulo, Centro Brasileiro de Análise e Planejamento (Cebrap), v. 3, n. 64, p. 132-140, 2002.

VIEIRA, S. Política(s) e gestão da educação básica: revisitando conceitos simples. RBPAE, v. 23, n. 1, p. 53-69, jan./abr. 2007.

Sobre os autores:

Ruy Mello Neto é doutor em Educação pela Faculdade de Educação da USP. Atua como pesquisador.

E-mail:reyneto@gmail.com

Hugo Augusto Medeiros é doutorando em Educação pela UFPE e gestor governamental da Secretaria de Planejamento e Gestão do governo do estado de Pernambuco (Seplag/PE).

E-mail: hugomedeiros.seplag@gmail.com

Maria Helena Lira é doutora em Educação pela Universidade Federal de Pernambuco (UFPE) e professora adjunta da Universidade Federal Rural de Pernambuco (UFRPE)

E-mail: mhelenalira@gmail.com

Fernanda Maria Mello é mestra em Saúde Pública pela Universidade de São Paulo (USP). Atua como pesquisadora.

E-mail: fernandambraga@gmail.com

Fábio Paiva é doutor em Educação pela UFPE e professor Assistente - UFPE.

E-mail: oracullo@gmail.com

Flávia Manuella de Oliveira é doutoranda em Psicologia pelo Instituto de Psicologia da USP.

E-mail: flavia.muo@gmail.com

Recebido em: maio de 2016

Aprovado em: junho de 2016 